\title{
Short sleep duration is associated with teacher-reported inattention and cognitive problems in healthy school-aged children
}

This article was published in the following Dove Press journal:

Nature and Science of Sleep

6 March 2012

Number of times this article has been viewed

\author{
Reut Gruber ${ }^{1,2}$ \\ Sonia Michaelsen ${ }^{1,2}$ \\ Lana Bergmame ${ }^{2}$ \\ Sonia Frenette ${ }^{3,4}$ \\ Oliviero Bruni ${ }^{5}$ \\ Laura Fontil ${ }^{2}$ \\ Julie Carrier ${ }^{3,4}$
}

'Department of Psychiatry, McGill University, ${ }^{2}$ Attention, Behavior and Sleep Lab, Douglas Mental Health University Institute, ${ }^{3}$ Centre du Sommeil et des Rythmes Biologiques, Hôpital du Sacré-Coeur de Montréal, ${ }^{4}$ Departement de Psychologie, Université de Montréal, Montreal, QC, Canada; ${ }^{5}$ Child Neuropsychiatry Unit, University of Rome, Rome, Italy

Correspondence: Reut Gruber Department of Psychiatry, McGill University, Douglas Mental Health University Institute, 6875 LaSalle Boulevard, Verdun, Montreal, Quebec H4H IR3, Canada $\mathrm{Tel}+|5| 476|6| 3 \mid$ ext 3476 Fax $+|5| 47623858$

Email reut.gruber@douglas.mcgill.ca
Purpose: Pediatric, clinical, and research data suggest that insufficient sleep causes tiredness and daytime difficulties in terms of attention-focusing, learning, and impulse modulation in children with attention deficit hyperactivity disorder (ADHD) or in those with ADHD and primary sleep disorders. The aim of the present study was to examine whether sleep duration was associated with ADHD-like symptoms in healthy, well-developing school-aged children.

Patients and methods: Thirty-five healthy children (20 boys, 15 girls), aged 7-11 years participated in the present study. Each child wore an actigraphic device on their nondominant wrist for two nights prior to use of polysomnography to assess their typical sleep periods. On the third night, sleep was recorded via ambulatory assessment of sleep architecture in the child's natural sleep environment employing portable polysomnography equipment. Teachers were asked to report symptoms of inattention and hyperactivity/impulsivity on the revised Conners Teacher Rating Scale.

Results: Shorter sleep duration was associated with higher levels of teacher-reported ADHDlike symptoms in the domains of cognitive problems and inattention. No significant association between sleep duration and hyperactivity symptoms was evident.

Conclusion: Short sleep duration was found to be related to teacher-derived reports of ADHDlike symptoms of inattention and cognitive functioning in healthy children.

Keywords: ADHD-like symptoms, sleep duration, inattention, hyperactivity, impulsivity, healthy school-aged children

\section{Introduction}

A considerable proportion of elementary school-aged children sleep for less than the recommended 10-11 hours. ${ }^{1}$ For example, a study conducted in 2004 found that $43 \%$ of boys aged 10-11 years slept for less than 9 hours per night. ${ }^{2}$ Decreases in sleep time combined with increasingly delayed bedtimes suggest that sleep restriction is emerging as a preadolescent problem. A poll conducted by the National Sleep Foundation found that adolescents (6th-12th grade) averaged 0.5-2 hours less than the recommended amount of sleep each night. ${ }^{3}$ This finding is a major problem, given the negative impact of restricted sleep on the mental and physical health of children and adolescents.

Mounting evidence indicates that sleep has beneficial effects on learning, memory, attention, emotional regulation, and academic success. Conversely, fatigue and insufficient sleep can negatively affect academic performance, self-regulation, and attention, all of which are necessary for success in school (for a review see Gruber et al). ${ }^{4}$ The aspects of human behavior most affected by fatigue and insufficient sleep are the executive functions, learning, and memory; these are also the key functional 
domains required for academic success. Sleep loss impairs performance on tasks requiring abstract thinking, creativity, integration, and planning, ${ }^{5}$ and is associated with a decrease in the efficiency of learning and memory. ${ }^{6-13}$

Furthermore, pediatric, clinical, and research data suggest that insufficient sleep causes tiredness and daytime difficulties in terms of attention-focusing and impulse modulation. ${ }^{14-17}$ In 1991, Dahl et $\mathrm{al}^{18}$ observed that such difficulties were very similar to the core symptoms of attention deficit hyperactivity disorder (ADHD), the most commonly diagnosed neuropsychological disorder in children. Subsequently, several researchers have studied the association between sleep and neurobehavioral functioning in children with ADHD with or without sleep-disordered breathing and in children with both ADHD and restless leg syndrome/periodic leg movement disorder. ${ }^{14,19-22}$ The cited studies consistently demonstrated that, in such populations, sleep disruption was associated with hyperactivity and inattention. ${ }^{22}$

Although the cited works provide convincing evidence that sleep and attention interact in children with ADHD, or in those with ADHD and any or all of sleep apnea, sleepdisordered breathing, restless leg syndrome, and periodic leg movement disorder, it is not clear whether this is true of typically developing children that do not suffer from any such problems. The few survey- or actigraphy-based studies that have examined the association between short sleep duration and ADHD-like symptoms in typically developing children have yielded conflicting results. ${ }^{23-28}$ Inconsistent data were evident in both types of studies, with some reports finding associations between short sleep duration and inattention ${ }^{23,24,26,29,30}$ and hyperactivity, ${ }^{25,27,28}$ whereas others did not. ${ }^{23-25,31,32}$ Reasons for such inconsistencies could be related to methodological differences in the way that sleep was measured. Polysomnography (PSG) was not employed, and no study employed an objective measure of breathing symptoms, and no prior study has measured restless leg syndrome or periodic leg movement disorder using either objective or subjective measures. Breathing symptoms, restless leg syndrome, and periodic leg movement disorder are common conditions, but relatively underdiagnosed in pediatric populations ${ }^{33}$ and have been frequently associated with inattention and hyperactivity. ${ }^{34-38}$

Therefore, the presence of such comorbidities may have confounded prior study results, contributing to inconsistent findings. It is therefore impossible to draw firm conclusions in terms of an association between short sleep duration and symptoms of inattention and hyperactivity/impulsivity in healthy children based on the data of the cited works. This is important because if short sleep duration is indeed associated with ADHD-like symptoms in typically developing children who do not have primary sleep disorders, identification of such an association would support the use of interventions aimed at reducing sleep deprivation. These interventions could therefore help otherwise healthy children to fulfill their potential.

The goal of the present study was to determine whether shorter sleep duration was related to symptoms of inattention and hyperactivity/impulsivity, which are commonly used in the diagnosis of ADHD, in typically developing children. It was hypothesized that shorter sleep duration would be associated with higher teacher ratings of inattention and hyperactivity/impulsivity.

\section{Material and methods \\ Participants}

Thirty-five children (20 boys, 15 girls) aged 7-11 years (mean 8.60 years; standard deviation [SD] 1.12 years) participated in the present study. Psychiatric status was assessed using the Diagnostic Interview Schedule for Children; ${ }^{39}$ which was administered to parents. Medical information was obtained via a detailed health screening form. Participants were excluded if they had an intelligence quotient (IQ) $<80$ (measured using the Wechsler Intelligence Scale for Children, 4 th edition ${ }^{40}$ ), or any medical or psychiatric conditions. In addition, children with a saturation nadir lower than $90 \%$, with paradoxical breathing, or with periodic limb movements associated with five or more leg movements per hour of sleep were excluded from the study.

Participants were recruited from elementary schools located in districts of middle socioeconomic status. The study was approved by the Research Ethics Board of the Douglas Mental Health University Institute. All enrolled children completed the study. Each child received compensation of CAD75. Parents signed consent forms permitting research team members to contact teachers. In addition, parents sent teachers information on the study, and informed them that team members would be in contact seeking completion of questionnaires. All teachers were contacted by a research assistant and subsequently completed the revised Conners Teacher Rating Scale (CTRS-R). ${ }^{41}$

\section{Procedure}

Children were first screened for eligibility. During initial contact, over-the-phone assessment was conducted using the Pediatric Sleep Questionnaire ${ }^{42}$ which assesses sleepdisordered breathing, snoring, and sleepiness. In addition, 
the Chervin and Hedger tool, ${ }^{43}$ which investigates leg restlessness, experience of growing pains in bed, insomnia, and morning headache, was administered to exclude those with restless leg syndrome. Children scoring 0.33 or higher (ie, replying positively to $33 \%$ or more of the 22 questions of either scale) were excluded. Health-related conditions and use of medication were assessed using a health screening form that included a detailed list of questions about each child's health status. Children who passed over-the-phone screening next visited the laboratory, where both IQ and potential psychological diagnoses were evaluated in a quiet room. After initial screening, children meeting inclusion criteria were invited to participate in the study and their parents received a package that included a sleep assessment battery, a demographic questionnaire, and a consent form. Sleep assessment included use of the morningness-eveningness questionnaire, ${ }^{44}$ actigraphy, and a sleep log. Parents were asked to complete and return the questionnaire. Teachers were requested to complete the CTRS-R ${ }^{41}$ based on the week of sleep evaluation. Each child wore an actigraphic device on their nondominant wrist for a period of two nights prior to use of PSG, to assess their usual sleep period. On the third night, sleep was recorded using ambulatory assessment of sleep architecture employing portable PSG equipment. On the scheduled night, a sleep technician arrived at each child's home 1.5 hours prior to habitual bedtime and connected the sleep recording apparatus. Recording commenced at the child's habitual bedtime. Sleep pattern and architecture were recorded in the natural home environment because such data afford greater ecological validity than do records logged in sleep laboratories. ${ }^{45-47}$ For a visual representation of the study design, please see Figure 1.

\section{Measures}

Questionnaires/scales for neurobehavioral assessment ADHD-like symptoms were evaluated using the CTRS-R, a well-validated and reliable instrument used to screen for ADHD in children. ${ }^{41}$ The CTRS-R has internal consistency ratings of $0.86-0.95$ and high test-retest reliability. ${ }^{41}$ Teachers rated several behaviors on a scale from zero (not true at all) to three (very true), yielding four indices; data from the hyperactivity-impulsivity and cognitive problems/inattention domains were focused on.

The Full Scale IQ score of the Wechsler Intelligence Scale for Children, 4 th edition ${ }^{40}$ was used to estimate general cognitive functioning.

\section{Sleep assessment PSG}

An in-home recording procedure was used to assess child sleep architecture, to allow children to sleep in their natural environment. PSG recordings were performed in the children's homes using a digital ambulatory sleep recorder

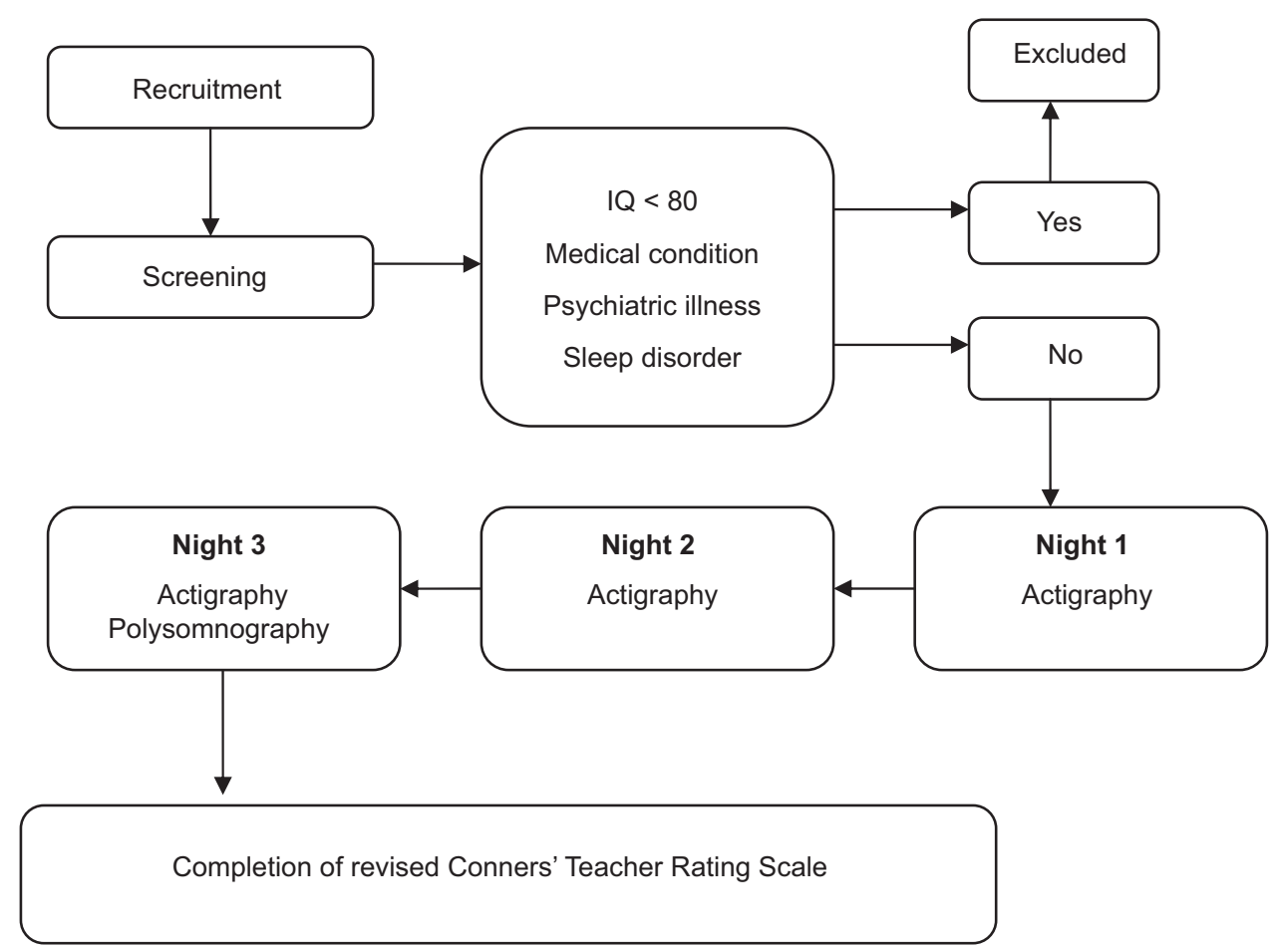

Figure I Study design. 
(Vitaport-3; TEMEC Instruments BV, Kerkrade, the Netherlands), measuring electroencephalography, submental electromyography, electrooculography, and finger pulse oximetry. Electroencephalography electrodes were placed bilaterally along the anteroposterior axes at locations F3, $\mathrm{F} 4, \mathrm{C} 3, \mathrm{C} 4, \mathrm{P} 3, \mathrm{P} 4, \mathrm{O} 1$, and $\mathrm{O} 2$. To assess respiration, two respiratory belts, measuring both chest and abdominal movement, were fitted to detect hypopnea and apneas, respectively, and pulse oximetry was used to measure oxygen saturation. The decision not to use cannula was based on the fact that, whereas the electrooculography, electromyography, and electroencephalography electrodes could be easily twisted together and attached to the recording equipment located close to the child's head, the use of nasal cannula would interfere with the child's sleep and would impact the ecological validity of the study.

Electromyography leg electrodes were used to identify leg-movements. Sleep stages were scored visually onscreen (LUNA; Stellate Systems, Montreal, Canada) using the C3 derivation (referential derivation: linked ears) according to standard criteria, ${ }^{48}$ but employing 20 -second epochs.

Various PSG sleep measures were analyzed, but, in the present study, sleep duration was focused on.

\section{Actigraphic measurements}

Actigraphs (Actiwatch ${ }^{\circledR}$ 64; Mini Mitter Company Inc, Bend, OR) were used to assess sleep patterns in the natural home environment. These computerized wristwatch-like devices collect data generated by movement. Their use is minimally invasive and the devices therefore allow sleep to be reliably recorded without interfering with family routine. Each actigraphic sleep interval was manually marked with sleep log bedtime and rising time. For each 1-minute epoch, a total activity count was computed. If a threshold value was attained, then the epoch was considered to be wakefulness. If the value fell below that threshold, then the epoch was considered to be sleep. Actigraphic data were analyzed using Actiwatch 64 sleep software (Mini Mitter). The actigraphic parameter of interest was sleep period, representing the amount of time between sleep commencement and wakening. Sleep start and sleep end were automatically determined as the first and last 5-minute periods, respectively, in which no more than a single epoch was scored as mobile.

\section{Circadian preference measure}

The Children's Morningness-Eveningness Preferences Scale, ${ }^{49}$ a ten-item multiple-choice scale adapted from the Horne-Ostberg morningness-eveningness questionnaire, ${ }^{44}$ was used to determine circadian preference. The scale ranges from ten (extreme evening preference) to 42 (extreme morning preference).

\section{General evaluation and confounders}

To characterize the profiles of the children and reconfirm that the psychological profiles of the study children were within the normal range, the Child Behavior Checklist was used, a frequently utilized dimensional measure of child psychopathology. ${ }^{50,51}$ Numerous studies have confirmed the stability of the instrument in terms of psychometric properties; the test shows good reliability and validity in both clinical and nonclinical populations. ${ }^{52,53}$

Body mass index was calculated by dividing weight in kilograms by height in meters squared.

\section{Statistical analyses}

Descriptive statistics on demographics, physical, and intellectual characteristics of participants were computed. To determine whether sleep duration on the PSG night was similar to those on the weeknights preceding PSG, Student's $t$-test for related samples was used to compare the mean time in bed obtained in the two consecutive nights prior to PSG to the time spent in bed in the PSG night. Multiple linear regression analyses, adjusted for age, IQ, body mass index, and circadian tendency, were used to assess the strength of potential relationships between teacher reports of inattention/cognitive problems or hyperactivity (dependent variables) and total sleep duration as measured by PSG (independent variable). All analyses were performed using IBM SPSS (v 15.0 for Windows; SPSS Inc, Chicago, IL). $P<0.05$ was considered significant.

\section{Results}

Demographic and sleep characteristics of all enrolled participants are presented in Table 1 . The age range was 7-11 years (mean 8.60 years, SD 1.12 years). Twenty (57\%) of the children were male. Caucasian children represented $68.6 \%$ of enrolled participants, $2.9 \%$ had an African-American background, $8.6 \%$ were Asian, and $8.6 \%$ of mixed race. The average total score on the Child Behavior Checklist ${ }^{50-53}$ was 49.77 (SD 9.2), thus confirming that all participants were within the normal range (T score $<60$ ) on all subscales pertaining to child behavior. All of the participants who were included in the study were below the cutoff score on the Pediatric Sleep Questionnaire, ${ }^{42}$ had no indication of desaturation, and no paradoxical breathing at the thoracic and abdominal channels (Table 1).

The average time slept in bed on the first two nights of actigraphic measurement was 539.64 minutes (SD 59.96 minutes) 
Table I Sleep, demographic, and clinical characteristics (frequency or mean \pm standard deviation) of the sample $(n=35)$

\begin{tabular}{|c|c|}
\hline Variable & $\begin{array}{l}\text { Mean } \pm \text { SD } \\
\text { (or frequency) }\end{array}$ \\
\hline \multicolumn{2}{|l|}{ Sleep characteristics } \\
\hline \multicolumn{2}{|l|}{ Actigraphy } \\
\hline Sleep period (first two nights) & 539.64 (minutes) \pm 59.96 \\
\hline Sleep period (third night) & 533.54 (minutes) \pm 59.65 \\
\hline \multicolumn{2}{|l|}{ PSG } \\
\hline Sleep duration (third night, PSG data) & 523 (minutes) \pm 54.69 \\
\hline Stage $1 \%$ & $3.45 \pm 1.80$ \\
\hline Stage $2 \%$ & $43.56 \pm 7.03$ \\
\hline Stage $3 \%$ & $13.19 \pm 3.70$ \\
\hline Stage $4 \%$ & $21.66 \pm 5.54$ \\
\hline REM \% & $18.14 \pm 3.28$ \\
\hline Sleep efficiency & $95.88 \pm .302$ \\
\hline Oxygen saturation (minimum) & $94.3 \pm 1.7$ \\
\hline Oxygen saturation (mean) & $97.8 \pm .62$ \\
\hline PLM index & $1.83 \pm 1.42$ \\
\hline MES chronotype score & $31.06 \pm 3.75$ \\
\hline \multicolumn{2}{|l|}{ Demographic characteristics } \\
\hline Gender (male/female) & $20 / 15$ \\
\hline Age & $8.6 \pm 1.12$ \\
\hline BMI & $18.44 \pm 4.05$ \\
\hline \multicolumn{2}{|l|}{ Ethnic background } \\
\hline Caucasian & 24 \\
\hline African & I \\
\hline Asian & 3 \\
\hline Multiethnic & 3 \\
\hline Unknown & 4 \\
\hline \multicolumn{2}{|l|}{ Clinical characteristics } \\
\hline IQ & $104.54 \pm 17.99$ \\
\hline CBCL score & $49.77 \pm 9.2$ \\
\hline CTRS-R cognitive problems/inattention & $48.46 \pm 5.65$ \\
\hline \multicolumn{2}{|l|}{ T score } \\
\hline CTRS-R hyperactivity-impulsivity $T$ score & $48.32 \pm 6.04$ \\
\hline
\end{tabular}

Abbreviations: BMI, body mass index; CBCL, Child Behavior Checklist; CTRS-R, revised Conners Teacher Rating Scale; IQ, intelligence quotient; MES, MorningnessEveningness Preferences Scale; PLM, periodic limb movement; PSG, polysomnography; REM, rapid eye movement; SD, standard deviation.

and 533.54 minutes (SD 59.65 minutes) on the PSG night. Sleep duration measured by PSG was 528 minutes (SD 54.69 minutes). No gender or racial difference was evident in average sleep period or average sleep duration.

No significant difference between the sleep period in the two nights preceding PSG evaluation and the sleep period of the PSG night measured by PSG $(t[27]=-0.16 ; P>0.05)$ was evident. In addition, significant correlation between sleep period, as measured by actigraphy on the PSG night, and sleep duration measured by PSG was found ( $r=0.74$, $P<0.005)$.

To explore whether sleep duration contributed to ADHD-like symptoms in healthy well-developing children, multiple linear regression analyses were performed (Table 2). Multiple linear
Table 2 Results of regression analyses studying main effects of sleep duration on cognitive problems/inattention and hyperactivityimpulsivity on the revised Conners Teacher Rating Scale

\begin{tabular}{|c|c|c|}
\hline \multirow[t]{2}{*}{ Measure } & \multirow{2}{*}{$\begin{array}{l}\text { Cognitive } \\
\text { problems/inattention } \\
\beta\end{array}$} & \multirow{2}{*}{$\begin{array}{l}\text { Hyperactivity- } \\
\text { impulsivity } \\
\beta\end{array}$} \\
\hline & & \\
\hline \multicolumn{3}{|l|}{ Control (model I) } \\
\hline Age & -0.22 & -0.12 \\
\hline BMI & -0.02 & -0.21 \\
\hline MES score & 0.20 & 0.20 \\
\hline WISC-IV IQ score & $-0.43^{*}$ & -0.29 \\
\hline Gender & 0.22 & 0.18 \\
\hline Total $R^{2}$ (adjusted) & $0.28^{*}$ & 0.10 \\
\hline$\Delta R^{2}$ & $0.38^{*}$ & 0.25 \\
\hline \multicolumn{3}{|c|}{ Main effect (model 2) } \\
\hline Age & -0.25 & -0.04 \\
\hline BMI & -0.034 & -0.40 \\
\hline MES score & 0.23 & 0.35 \\
\hline WISC-IV IQ score & -0.31 & -0.34 \\
\hline Gender & 0.11 & 0.17 \\
\hline Sleep duration & $-0.49 *$ & -0.47 \\
\hline Stage $1 \%$ & 0.29 & 0.08 \\
\hline Stage $2 \%$ & 0.08 & 0.01 \\
\hline Stage 3\% & -0.03 & 0.35 \\
\hline Stage $4 \%$ & 0.03 & -0.05 \\
\hline REM \% & 0.09 & $0.58^{*}$ \\
\hline Sleep efficiency & 0.15 & 0.05 \\
\hline Total $R^{2}$ (adjusted) & $0.49 *$ & 0.17 \\
\hline$\Delta R^{2}$ & $0.27 *$ & 0.23 \\
\hline
\end{tabular}

Notes: $* P \leq 0.05 ; \beta$ represents standardized partial regression coefficients; $R^{2}$ values refer to the variation accounted for by the model; $\Delta R^{2}$ refers to $R^{2}$ change.

Abbreviations: BMI, body mass index; IQ, intelligence quotient; MES, MorningnessEveningness Preferences Scale; REM, rapid eye movement; WISC-IV, Wechsler Intelligence Scale for Children, 4th edition.

regression analysis revealed that the addition of sleep duration, percentage of sleep stages, and sleep efficacy to the model significantly increased the $R^{2}$ value, contributing $27 \%$ to the explained variance $\left(R^{2}=0.65 ; P<0.05\right)\left(\Delta R^{2}=0.27\right)\left(F_{\text {change }}\right.$ $[1,29]=3 ; P<0.05)$ after controlling for body mass index, circadian tendency, and IQ in predicting cognitive problems/inattention. Sleep duration was found to be a significant predictor in the model predicting scores on teacher-reported cognitive problems and inattention; individuals with shorter sleep duration received higher scores on this scale.

Sleep variables measured by PSG did not contribute significantly to the prediction of teacher-derived data on hyperactivity.

\section{Discussion}

The aim of the present study was to explore whether objective measures of sleep duration are associated with teacher ratings of inattention and hyperactivity/impulsivity in healthy, well-developing preadolescent school-aged children who 
do not suffer from sleep-disordered breathing, restless leg syndrome, or periodic leg movement disorder. The results showed that shorter sleep duration was associated with higher levels of teacher ratings of cognitive problems and inattention. Specifically, short sleep duration, objectively measured using PSG, was significantly related to teacher reports of difficulties in the realms of learning or memory, in organizational skills, and the ability to be attentive when required. However, no significant association between sleep duration and hyperactivity symptoms was evident.

Several previous reports have found that short sleep duration was related to poorer academic performance when measures such as the Standard Achievement Test scores or school grades were employed (for reviews, see Gruber et al, ${ }^{4}$ Dewald et al, ${ }^{54}$ and Wolfson and Carskadon $\left.{ }^{55,56}\right)$. The present findings add to such data by demonstrating a strong association between sleep duration and the day-to-day functioning of children in the school environment, as reported by teachers, who were blind to the sleep status of participants. Both lines of investigation converge to show that shorter sleep is associated with the manifestation of inattention and poorer school-related outcomes. However, the mechanisms underlying these associations remain unclear, which is an important question that needs to be addressed in future research.

The findings are consistent with previous data from studies conducted in healthy adults, which found that deficits resulting from sleep deprivation resemble those seen in patients with prefrontal cortex damage. ${ }^{57}$ The prefrontal cortex plays a significant role in executive functions, ${ }^{58,59}$ and sleep loss preferentially impairs functions governed by the prefrontal cortex. Considering that a deficit in executive functions and prefrontal cortex activity is a core feature associated with ADHD, ${ }^{60-64}$ it is not surprising that short sleep duration in healthy children is associated with ADHD-like symptoms. However, because the present study was correlational in nature, the causes and effects were unable to be determined.

In contrast to the conclusions of previous reports, ${ }^{27,28}$ short sleep duration was not associated with the manifestation of higher levels of hyperactivity in the present sample of typically developing, non-ADHD school-aged children. Although this is not consistent with previous suggestions regarding the potential impact of sleep deprivation on selfregulation, ${ }^{65-67}$ the data are in line with those of recent studies showing that different functional domains are differentially affected by sleep deprivation. ${ }^{68}$ The variations in the association between sleep duration and ADHD-like symptoms emphasize the need to better explore these relationships, as well as to better understand the underlying mechanisms. ${ }^{68}$
Sleep duration contributed $27 \%$ to the explained variance in inattention and cognitive problems even after IQ was considered. If sleep duration is so significantly associated with the manifestation of such ADHD-like symptoms in otherwise healthy children, it is possible that increasing sleep duration might offer an effective and inexpensive opportunity to optimize the school functioning of healthy children. Sleep does not cost money and does not have any negative side effects. A potential practical path to this end is to incorporate sleep education into the practice of health care providers and pediatricians, and into the health curricula of elementary schools, similar to Cain et al's efforts at establishing motivational school-based interventions. ${ }^{69}$ In addition, it is critical to educate parents, students, educators, and clinicians on the importance of sleep and to develop tools aimed at preventing sleep deprivation.

The present study extends prior research in various ways. First, sleep was objectively assessed and an ecologicallybased measure of ADHD-like symptoms at school was employed. In addition, healthy school-aged children were studied, excluding those with symptoms of primary sleep disorders or ADHD. Further, sleep parameters were measured at home, increasing the ecological validity of the results.

\section{Limitations}

Some limitations of this work are apparent. First, the participants were below the cutoff score on the Pediatric Sleep Questionnaire, had no indication of desaturation, and no paradoxical breathing at the thoracic and abdominal channels; however, the presence of sleep-disordered breathing cannot be completely excluded because of the lack of nasal cannula or thermistor. Second, even if a statistical power analysis indicated that the sample size was sufficient for detection of significant effects, the sample size was still relatively small and the results are thus preliminary in nature.

The data support an association between sleep duration and school cognitive performance; however, the mechanisms and potential causes and effects of such association require further exploration. Although sleep duration explained $27 \%$ of variance, there are, clearly, additional variables that affect inattention and cognition in healthy children. Future studies are needed to further identify such variables.

Sleep is also affected by the physical and emotional environment of the child/adolescent. Exposure to light or to an uncomfortable temperature in the evening, a high level of stimulation around bedtime, and a noisy environment have all been shown to compromise the ability to obtain sufficient sleep. In addition to physical features, the emotional 
environment, affected principally by family interactions (eg, marital conflict), also has a significant impact on sleep processes. ${ }^{70}$ In the present study, interference with regular sleep habits and the sleep environment was minimized by using at-home measurement of sleep parameters. However, environmental factors that might impact child sleep were not able to be identified. Future studies should further delimit the physical and environmental factors contributing to shortening of preadolescent sleep duration.

\section{Conclusion}

The findings suggest that short sleep duration is related to teacher-derived reports of ADHD-like symptoms of inattention and cognitive functioning in healthy children. The negative impact of sleep deprivation emphasizes the need to provide children and their parents with education on healthy sleep and tools that assist in achieving such sleep.

\section{Acknowledgments}

This study was supported by grants to Dr Gruber from the Canadian Institutes of Health Research (CIHR; grant number 153139) and the Fonds de la recherche en santé du Québec (FRSQ; grant number 10091).

\section{Disclosure}

The authors report no conflicts of interest in this work.

\section{References}

1. Heussler HS. Common causes of sleep disruption and daytime sleepiness: childhood sleep disorders II. Med J Aust. 2005;182(9):484-489.

2. Spilsbury JC, Storfer-Isser A, Drotar D, et al. Sleep behavior in an urban US sample of school-aged children. Arch Pediatr Adolesc Med. 2004;158(10):988-994.

3. National Sleep Foundation. 2006 teens and sleep: sleep in America poll. 2006. Available from: http://www.sleepfoundation.org/article/ sleep-america-polls/2006-teens-and-sleep. Accessed July 20, 2010.

4. Gruber R, Wiebe ST, Wells SA, Cassoff J, Monson E. Sleep and academic success: mechanisms, empirical evidence, and interventional strategies. Adolesc Med State Art Rev. 2010;21(3):522-541.

5. Dahl RE. The regulation of sleep and arousal: development and psychopathology. Dev Psychopathol. 1996;8(1):3-27.

6. Curcio G, Ferrara M, De Gennaro L. Sleep loss, learning capacity and academic performance. Sleep Med Rev. 2006;10(5):323-337.

7. Maquet P, Laureys S, Peigneux P, et al. Experience-dependent changes in cerebral activation during human REM sleep. Nat Neurosci. 2000; 3(8):831-836.

8. Marshall L, Born J. The contribution of sleep to hippocampus-dependent memory consolidation. Trends Cogn Sci. 2007;11(10):442-450.

9. Ofen N, Kao YC, Sokol-Hessner P, Kim H, Whitfield-Gabrieli S, Gabrieli JD. Development of the declarative memory system in the human brain. Nat Neurosci. 2007;10(9):1198-1205.

10. Ribeiro S, Nicolelis MA. Reverberation, storage, and postsynaptic propagation of memories during sleep. Learn Mem. 2004;11(6):686-696.

11. Schabus M, Gruber G, Parapatics S, et al. Sleep spindles and their significance for declarative memory consolidation. Sleep. 2004;27(8): 1479-1485.
12. Stickgold R. Sleep-dependent memory consolidation. Nature. 2005; 437(7063):1272-1278.

13. Wilson MA, McNaughton BL. Reactivation of hippocampal ensemble memories during sleep. Science. 1994;265(5172):676-679.

14. Chervin RD, Dillon JE, Bassetti C, Ganoczy DA, Pituch KJ. Symptoms of sleep disorders, inattention, and hyperactivity in children. Sleep. 1997;20(12):1185-1192.

15. Corkum P, Moldofsky H, Hogg-Johnson S, Humphries T, Tannock R. Sleep problems in children with attention-deficit/hyperactivity disorder: impact of subtype, comorbidity, and stimulant medication. J Am Acad Child Adolesc Psychiatry. 1999;38(10):1285-1293.

16. O'Brien LM, Mervis CB, Holbrook CR, et al. Neurobehavioral correlates of sleep-disordered breathing in children. J Sleep Res. 2004; 13(2):165-172.

17. Stein MA. Unravelling sleep problems in treated and untreated children with ADHD. J Child Adolesc Psychopharmacol. 1999;9(3):157-168.

18. Dahl RE, Pelham WE, Wierson M. The role of sleep disturbances in attention deficit disorder symptoms: a case study. J Pediatr Psychol. 1991;16(2):229-239.

19. Archbold KH, Giordani B, Ruzicka DL, Chervin RD. Cognitive executive dysfunction in children with mild sleep-disordered breathing. Biol Res Nurs. 2004;5(3):168-176.

20. Bass JL, Corwin M, Gozal D, et al. The effect of chronic or intermittent hypoxia on cognition in childhood: a review of the evidence. Pediatrics. 2004;114(3):805-816.

21. Beebe DW, Gozal D. Obstructive sleep apnea and the prefrontal cortex: towards a comprehensive model linking nocturnal upper airway obstruction to daytime cognitive and behavioral deficits. J Sleep Res. 2002;11(1):1-16.

22. Melendres MC, Lutz JM, Rubin ED, Marcus CL. Daytime sleepiness and hyperactivity in children with suspected sleep-disordered breathing. Pediatrics. 2004;114(3):768-775.

23. Fallone G, Acebo C, Arnedt JT, Seifer R, Carskadon MA. Effects of acute sleep restriction on behavior, sustained attention, and response inhibition in children. Percept Mot Skills. 2001;93(1):213-229.

24. Fallone G, Acebo C, Seifer R, Carskadon MA. Experimental restriction of sleep opportunity in children: effects on teacher ratings. Sleep. 2005;28(12):1561-1567.

25. Gau SS, Kessler RC, Tseng WL. Association between sleep problems and symptoms of attention-deficit/hyperactivity disorder in young adults. Sleep. 2007;30(2):195-201.

26. Paavonen EJ, Porkka-Heiskanen T, Lahikainen AR. Sleep quality, duration and behavioral symptoms among 5-6-year-old children. Eur Child Adolesc Psychiatry. 2009;18(12):747-754.

27. Paavonen EJ, Raikkonen K, Lahti J, et al. Short sleep duration and behavioral symptoms of attention-deficit/hyperactivity disorder in healthy 7- to 8-year-old children. Pediatrics. 2009;123(5):e857-e864.

28. Touchette É, Petit D, Séguin JR, Boivin M, Tremblay RE, Montplaisir JY. Associations between sleep duration patterns and behavioral/cognitive functioning at school entry. Sleep. 2007;30(9):1213-1219.

29. Aronen ET, Paavonen EJ, Fjallberg M, Soininen M, Torronen J. Sleep and psychiatric symptoms in school-age children. J Am Acad Child Adolesc Psychiatry. 2000;39(4):502-508.

30. Epstein R, Chillag N, Lavie P. Starting times of school: effects on daytime functioning of fifth-grade children in Israel. Sleep. 1998;21(3): 250-256.

31. Nixon GM, Thompson JM, Han DY, et al. Short sleep duration in middle childhood: risk factors and consequences. Sleep. 2008;31(1):71-78.

32. Trabelsi S, Guillot S, Ritacco H, Boue F, Langevin D. Nano structures of colloidal complexes formed in oppositely charged polyelectrolyte/surfactant dilute aqueous solutions. Eur Phys J E Soft Matter. 2007;23(3):305-311.

33. Lumeng JC, Chervin RD. Epidemiology of pediatric obstructive sleep apnea. Proc Am Thorac Soc. 2008;5(2):242-252.

34. Beebe DW. Neurobehavioral morbidity associated with disordered breathing during sleep in children: a comprehensive review. Sleep. 2006;29(9):1115-1134. 
35. Chervin RD, Ruzicka DL, Giordani BJ, et al. Sleep-disordered breathing, behavior, and cognition in children before and after adenotonsillectomy. Pediatrics. 2006;117(4):e769-e778.

36. Cortese S, Konofal E, Yateman N, Mouren MC, Lecendreux M. Sleep and alertness in children with attention-deficit/hyperactivity disorder: a systematic review of the literature. Sleep. 2006;29(4):504-511.

37. Gozal D, Kheirandish-Gozal L. Neurocognitive and behavioral morbidity in children with sleep disorders. Curr Opin Pulm Med. 2007;13(6): 505-509.

38. Walters AS, Mandelbaum DE, Lewin DS, Kugler S, England SJ, Miller M. Dopaminergic therapy in children with restless legs/ periodic limb movements in sleep and ADHD. Pediatr Neurol. 2000; 22(3):182-186.

39. Shaffer D, Fisher P, Lucas CP, Dulcan MK, Schwab-Stone ME. NIMH Diagnostic Interview Schedule for Children Version IV (NIMH DISC-IV): description, differences from previous versions, and reliability of some common diagnoses. $J$ Am Acad Child Adolesc Psychiatry. 2000;39(1):28-38

40. Wechsler D. The Wechsler Intelligence Scale for Children. 4th ed. London: Pearson Assessment; 2004.

41. Conners CK, Sitarenios G, Parker JD, Epstein JN. Revision and restandardization of the Conners Teacher Rating Scale (CTRS-R): factor structure, reliability, and criterion validity. J Abnorm Child Psychol. 1998;26(4):279-291.

42. Chervin RD, Hedger K, Dillon JE, Pituch KJ. Pediatric Sleep Questionnaire (PSQ): validity and reliability of scales for sleep-disordered breathing, snoring, sleepiness, and behavioral problems. Sleep Med. 2000;1(1):21-32.

43. Chervin RD, Hedger KM. Clinical prediction of periodic leg movements during sleep in children. Sleep Med. 2001;2(6):501-510.

44. Horne JA, Ostberg O. A self-assessment questionnaire to determine morningness-eveningness in human circadian rhythms. Int $J$ Chronobiol. 1976;4(2):97-110.

45. Iber C, Redline S, Kaplan Gilpin AM, et al. Polysomnography performed in the unattended home versus the attended laboratory setting - Sleep Heart Health Study methodology. Sleep. 2004;27(3): 536-540.

46. Quan SF, Griswold ME, Iber C, et al. Short-term variability of respiration and sleep during unattended nonlaboratory polysomnography - the Sleep Heart Health Study. Sleep. 2002;25(8):843-849.

47. Quan SF, Howard BV, Iber C, et al. The Sleep Heart Health Study: design, rationale, and methods. Sleep. 1997;20(12):1077-1085.

48. Rechtschaffen A, Kales A, editors. A Manual of Standardized Terminology, Techniques and Scoring System of Sleep Scoring Stages of Human Subjects. Washington, DC: Public Health Service, US Government Printing Office; 1968.

49. Carskadon MA, Feifer R, Acebo C. Reliability of six scales in a sleep questionnaire for adolescents. Sleep Res. 1991;20:421.

50. Achenbach TM, Howell CT, Quay HC, Conners CK. National survey of problems and competencies among four- to sixteen-year-olds: parents' reports for normative and clinical samples. Monogr Soc Res Child Dev. 1991;56(3):1-131.

51. Bird HR. Epidemiology of childhood disorders in a cross-cultural context. J Child Psychol Psychiatry. 1996;37(1):35-49.
52. Jensen PS, Watanabe HK, Richters JE, et al. Scales, diagnoses, and child psychopathology: II. Comparing the CBCL and the DISC against external validators. J Abnorm Child Psychol. 1996;24(2):151-168.

53. Schmeck K, Poustka F, Dopfner M, et al. Discriminant validity of the child behaviour checklist CBCL-4/18 in German samples. Eur Child Adolesc Psychiatry. 2001;10(4):240-247.

54. Dewald JF, Meijer AM, Oort FJ, Kerkhof GA, Bogels SM. The influence of sleep quality, sleep duration and sleepiness on school performance in children and adolescents: a meta-analytic review. Sleep Med Rev. 2010;14(3):179-189.

55. Wolfson AR, Carskadon MA. Understanding adolescents' sleep patterns and school performance: a critical appraisal. Sleep Med Rev. 2003; 7(6):491-506.

56. Wolfson AR, Carskadon MA. Sleep schedules and daytime functioning in adolescents. Child Dev. 1998;69(4):875-887.

57. Horne JA. Human sleep, sleep loss and behaviour. Implications for the prefrontal cortex and psychiatric disorder. Br J Psychiatry. 1993; $162: 413-419$.

58. Kane MJ, Engle RW. The role of prefrontal cortex in working-memory capacity, executive attention, and general fluid intelligence: an individualdifferences perspective. Psychon Bull Rev. 2002;9(4):637-671.

59. Robbins TW. Dissociating executive functions of the prefrontal cortex. Philos Trans R Soc Lond B Biol Sci. 1996;351(1346):1463-1470.

60. Arnsten AF. Toward a new understanding of attention-deficit hyperactivity disorder pathophysiology: an important role for prefrontal cortex dysfunction. CNS Drugs. 2009;23 Suppl 1:33-41.

61. Barkley RA. Genetics of childhood disorders: XVII. ADHD, Part 1: the executive functions and ADHD. J Am Acad Child Adolesc Psychiatry. 2000;39(8):1064-1068.

62. Berlin L, Bohlin G, Nyberg L, Janols LO. How well do measures of inhibition and other executive functions discriminate between children with ADHD and controls? Child Neuropsychol. 2004;10(1):1-13.

63. Brennan AR, Arnsten AF. Neuronal mechanisms underlying attention deficit hyperactivity disorder: the influence of arousal on prefrontal cortical function. Ann N Y Acad Sci. 2008;1129:236-245.

64. Wodka EL, Mostofsky SH, Prahme C, et al. Process examination of executive function in ADHD: sex and subtype effects. Clin Neuropsychol. 2008;22(5):826-841.

65. Dahl RE. Sleeplessness and aggression in youth. J Adolesc Health. 2006;38(6):641-642.

66. Ireland JL, Culpin V. The relationship between sleeping problems and aggression, anger, and impulsivity in a population of juvenile and young offenders. J Adolesc Health. 2006;38(6):649-655.

67. Umlauf MG, Bolland JM, Lian BE. Sleep disturbance and risk behaviors among inner-city African-American adolescents. J Urban Health. 2011;88(6):1130-1142.

68. Tucker AM, Whitney P, Belenky G, Hinson JM, Van Dongen HP. Effects of sleep deprivation on dissociated components of executive functioning. Sleep. 2010;33(1):47-57.

69. Cain N, Gradisar M, Moseley L. A motivational school-based intervention for adolescent sleep problems. Sleep Med. 2011;12(3):246-251.

70. El-Sheikh M. Sleep and Development: Familial and Socio-cultural Considerations. New York: Oxford University Press; 2011.
Nature and Science of Sleep

\section{Publish your work in this journal}

Nature and Science of Sleep is an international, peer-reviewed, open access journal covering all aspects of sleep science and sleep medicine, including the neurophysiology and functions of sleep, the genetics of sleep, sleep and society, biological rhythms, dreaming, sleep disorders and therapy, and strategies to optimize healthy sleep. The journal welcomes

\section{Dovepress}

original research, clinical \& epidemiological studies, reviews \& evaluations, case reports and extended reports. The manuscript management system is completely online and includes a very quick and fair peerreview system, which is all easy to use. Visit http://www.dovepress.com/ testimonials.php to read real quotes from published authors. 